\title{
A ciência e a produção de conhecimento na pesquisa educacional: contribuiçóes de Maria Célia Marcondes de Moraes
}

\author{
Patricia Laura Torriglia* \\ Newton Duarte**
}

\section{Resumo}

O presente texto apresenta alguns pontos relevantes acerca dos problemas da ciência e da produção de conhecimento em Educação assinalados em diferentes obras escritas pela Dra. Maria Célia Marcondes de Moraes. Diversos problemas teóricos preocuparam a autora, em especial, o do ceticismo vigente e as profundas contradiçóes nas quais os sentidos e conceitos - que significam movimentos teórico-práticos do real - se apresentam com sutis e marcadas inversóes impactando o campo e a pesquisa educacional. Com base em uma perspectiva ontológica materialista e crítica Moraes indagou e aprofundou estas questóes, e em especial, discutiu o papel do ser educação em sua máxima expressão.

Palavras-chave: Ciência. Produção do conhecimento. Moraes, Maria Célia Marcondes de.

* Doutora em Educação pela Universidade Federal de Santa Catarina (UFSC). Professora Adjunta II. Centro de Ciências da Educação. Universidade Federal de Santa Catarina. Coordenadora do Grupo de Estudos e Pesquisa em Ontologia Crítica (GEPOC/CED/ PPG), certificado pela UFSC no diretório de Grupos de Pesquisa do CNPq.

** Doutor em Educação pela Universidade Estadual de Campinas (Unicamp) Professor Titular. Universidade Estadual Paulista Júlio de Mesquita Filho (Unesp). Coordenador do Grupo de Pesquisa Estudos Marxistas em Educaçáo, certificado pela Unesp no diretório de Grupos de Pesquisa do CNPq. 
Marx (1865) assinala que é um paradoxo que a "terra se mova em volta do sole que a água seja constituida por dois gases altamente inflamáveis. A verdade cientifica é sempre um paradoxo do ponto de vista da experiência imediata que alcança apenas a mistificada aparência das coisas." (MORAES, 2007)

\section{Introduçáo}

Maria Célia Marcondes de Moraes procurava, com todas as contradições que o real tem, uma vida plena de sentido. Aqueles que a conheceram compreendem o porquê dessas palavras. Para quem náo teve a sorte de conhecê-la, poderá fazê-lo por meio de sua rica produção acadêmica.

Não pretendemos, neste texto, esgotar a riqueza das discussóes e contribuiçóes que a pesquisadora e professora realizou. Isso seria impossível, não somente pela complexidade e variedade de temas que abordou, mas porque nosso intuito é destacar alguns aspectos fundamentais da produção dessa incansável defensora da atividade de produção de conhecimento no campo educacional. ${ }^{1}$

Interessa-nos recuperar alguns pontos relevantes acerca dos problemas da ciência e da produção de conhecimento em Educação por ela assinalados e compartilhados por outros professores e estudantes, especificamente do Programa de Pós-Graduação em Educação da Universidade Federal de Santa Catarina (UFSC). Podemos afirmar que tais questóes se estenderam para outros pesquisadores e estudantes do Brasil, como é o caso da criação, em 2002, com um dos autores deste texto, do grupo de pesquisa Estudos Marxistas em Educação.

Diversos problemas teóricos preocuparam a autora, em especial, o do ceticismo vigente e das profundas contradiçóes nas quais sentidos e conceitos que significam movimentos teórico-práticos do real se apresentam com sutis e marcadas inversóes. $\mathrm{O}$ eixo presente em seus trabalhos acadêmicos e nas discussóes em sala de aula, em congressos, palestras, encontros - o "tema perseguido e a persecução de um tema” - era o da produção de conhecimento e o caminho ontológico para compreender o real, como explicou em sua última conferência. ${ }^{2}$ Assim, a gnosiologia se complementava com as questóes do ser. Com base em uma perspectiva ontológica materialista e crítica, 
Moraes indagou, discutiu e aprofundou questôes em torno do ser social em sua máxima expressão.

No campo educacional, discutiu a apreensão do real, as possibilidades de conhecer o mundo objetivo e a inter-relação do complexo educacional com a totalidade social. Moraes introduziu na Pós-Graduação em Educação, na UFSC, a Ontologia do ser social, de Lukács (1981), estudando e fortalecendo grupos de estudos. As primeiras discussōes foram sobre o capítulo "O trabalho" e, a seguir, difundiu textos que complementavam a perspectiva ontológica crítica de Lukács $(1978,1979,1984)$. Estes se completaram com obras de Marx (1964, 1983, 1974) e de autores contemporâneos, como Anderson, (1997), Wood (1998, 1999), Nanda (1997), Norris (1990, 1996, 1997, 1998), Jameson (1988), E. P. Thompson (1978, 1981), Bhaskar (1979, 1986, 1993, 1994, 1997), Ahmad (1995), entre outros.

Suas indagações teórico-metodológicas surgiram da reflexão sobre

- se é possível conhecer a realidade;

- como conhecer a realidade e

- como a área da educação estava discutindo tal processo.

Perguntava: a pesquisa tem avançado no conhecimento objetivo da educação? Essa pesquisa tem se distanciado da tentativa de conhecer a realidade? Os pesquisadores têm se contentado com descriçóes do cotidiano, em sua aparência e imediatismo, ou com os irracionalismos e subjetivismos conducentes à negação da objetividade do conhecimento?

A filosofia, gênese de sua formação, permeava sua incansável necessidade de conhecer os vestígios ocultos dos fenômenos e sua perseverança a levava - o tempo todo - a estar atenta às inquietaçóes de seu tempo histórico que, como sabemos, oscila entre ambíguas performances de uma sociabilidade cuja tendência é cada vez mais descartar o humano da humanidade.

Conhecer e fazer conhecer os debates da contemporaneidade era umas de suas finalidades. Compreender os temas, as perspectivas e as teses que se fazem presentes nas discussóes atuais no campo educacional era um desafio que se colocava e do qual não abria mão, incentivando permanentemente os estudantes a ampliarem o leque das discussóes. Explicava que era necessária a compreensão do momento atual, a percepção das perguntas que estão 
sendo postas e sua importância. Interessava discutir seu significado para um determinado momento histórico, sem esquecer a conjuntura, que está sempre em movimento. ${ }^{3}$

Não duvidava de que, sem a compreensão das contradições e do próprio momento histórico, a tendência seria a de se congelar a história, e, nessa estagnação, as categorias que se engendram na história ficariam comprometidas, apagando-se o campo de mediaçóes. Essa ocultação das mediaçôes acabaria por diluir a possibilidade de transformação do mundo ou por favorecer a instauração de proposiçôes que apenas reformam ou maquiam a realidade.

Do ponto de vista metodológico, era árdua a discussão que realizava sobre o lugar do sujeito e do objeto, procurando recuperar a ontologia do objeto sem ignorar a presença do sujeito que conhece. Moraes discutia a inteligibilidade do mundo, combatia o ceticismo, analisava o contraditório campo de mediaçóes para entender a produção e reprodução do social, temas defendidos com base na forte convicção de que o realismo é uma das possibilidades de superar o relativismo ontológico e as concepçóes empiricistas.

\section{Questóes de teoria e de método na pesquisa educacional}

Bem antes de entrar nos debates sobre a pesquisa na educação, Moraes buscava, apoiada nos estudos sobre a ontologia e o materialismo histórico, a gênese da crise da razão ocidental, as raízes da "agenda pósmoderna", as consequências da "virada linguística” e "pragmática” para a área da educação. Concordava com Lukács quando afirmava que o "[...] materialismo, na ontologia, implica não somente que ela venha livre daquelas turvaçóes provocadas pelas categorias lógicas e gnosiológicas, mas, também e sobretudo, que distinga de maneira inequívoca entre consideraçóes ontológicas e valorativas" (LUKÁCS, 1990, p. 31). Acrescenta que o método do marxismo, materialista, histórico e dialético, é um reflexo ontológicointelectivo da realidade. Nessa perspectiva, não se conformava em analisar o campo educacional sob o prisma dos limites do próprio campo. Afirmava que

Se nossa intenção é discutir "questōes de teoria e método na pesquisa em educação", talvez um bom ponto de partida seja a lembrança de que estamos 
diante de um campo minado. Poderíamos ficar a descrever as tendências, as novas perspectivas, os novos objetos, as novas metodologias - aspectos que, de todo modo, teremos que pelo menos apontar ao longo de nossas discussóes -, pois quer me parecer que as indagaçôes sobre o campo da pesquisa em educação não podem circunscrever-se a meras descrições. (MORAES, 2000, p. 1).

Assim, iniciava suas aulas sem desviar o foco da problemática mais profunda: a necessidade de discutir e compreender o que realmente significava a denúncia da falência do processo de modernização, a "suspeita sobre a confiança iluminista”, a não-confiança em uma razão capaz de construir sistemas de pensamento e de ação baseados em normas justas e coerentes, e a não-confiança na capacidade de os seres humanos organizarem de forma planejada e duradoura a ordem social e política. No escopo dessas ideias, afirmava ser imprescindível debater criticamente as concepçóes antirrepresentacionistas que negam a possibilidade de a teoria refletir a realidade, da mesma forma que negam à linguagem a qualidade de clareza e precisão. A linguagem, para essas concepçóes, seria sempre turva, e o conhecimento, sempre uma elaboração subjetiva.

Moraes introduzia estas problemáticas indicando a pertinência destas críticas que, contudo, se mostravam insuficientes por ocultar "[...] o complexo de forças históricas que determinam o desenvolvimento social". Insistia que figuravam na balança ideias difusas do Esclarecimento, sobretudo as ideias de Kant (1724-1804) e Condorcet (1743-1794). A propósito desta afirmação, ela escreveria que talvez fosse "[...] o ponto mais frágil da Agenda Pós-moderna e seu mais evidente pomo de discórdia: considerar as complexas determinaçóes das forças históricas uma metanarrativa e, ao desprezá-las, reduzir a uma narrativa sobre o único e o contingente" (MORAES, 2004, p. 342).

Estas premissas se complementavam com sua procura por compreender o processo de conhecimento da realidade. Como conhecer a inteligibilidade do mundo nesta complexa morte súbita de um tipo de racionalidade? Como conhecer a inteligibilidade do mundo no momento do aparecimento do discurso pós-moderno, que coloca a indeterminação total, a fragmentação da totalidade social e uma aposta na eliminação do campo das mediaçóes? 
O desafio era trazer de volta a discussão sobre a razão, o conhecimento objetivo e o projeto de emancipação da humanidade numa época marcada pela desilusão relativa às açóes transformadoras radicais, pela ocultação da verdade sobre a realidade social capitalista e pelo decreto da morte do sujeito.

Por essa razão, assinalava que, por um lado, “[...] nada mais há a ser objetivamente conhecido neste mundo relativo e fugaz, avesso a qualquer grand récit (Lyotard) ou interpretação totalizante. E do outro lado desta moeda temos a negação do agir e da práxis do sujeito humano e sua redução a uma subjetividade diluída, atomizada em redes flexíveis de jogos de linguagem" (MORAES, 1998, p. 1). Enfim, o que se propôe, indicava, são a fala e o olhar do desejo e da sensibilidade em contraposição às ilusóes da racionalidade e da objetividade.

Moraes tinha convicção de que, para entender-se a configuração de um determinado perfil de razão e dos esforços para sua desconstrução em tempos recentes, seria necessário compreender os processos de produção social, a divisão social do trabalho, as formas de propriedade, os avanços e a complexidade das forças produtivas, a configuração do capitalismo. Depois de cada mergulho nas razóes e nos porquês, ela complexificava as afirmaçóes dizendo: é impossível estabelecer uma relação causal direta entre a complexidade processual dos acontecimentos político-econômicos e a constituição da produção humana intelectual e artística.

Por essa via, discutia e introduzia a relação entre o conhecimento e as bases materiais, mostrando o campo do pensamento e do discurso próprio de determinada época, os processos e avanços do conhecimento e os métodos que permitiam o acesso ao conhecimento. Quando se referia, por exemplo, à cultura teocêntrica, articulava o método e as relaçóes de poder. Lembrava que, "[...] nesse contexto, o acesso ao conhecimento possuía um perfil bem definido: o método era o da hermenêutica, a interpretação do já visto, do já conhecido ou, melhor, do já revelado, e por certo, método acessível apenas aos padres da igreja. As concepçóes de tempo e de espaço -definidos pela finitude -, a legitimação religiosa do geocentrismo, criaturas feitas à imagem e semelhança de deus só poderiam viver no centro do universo [...] (MORAES, p. 2, 1998), indicando que a apresentação da produção artística completava a compreensão dessas relaçôes. Realizando um percurso histórico, questionava a concepção preconceituosa da Idade Média; mostrava o movimento de 1.000 anos 
dessa época, analisava o Renascimento e como a ideia de razão ocupou diferentes espaços e momentos no processo da história.

Finalizava esse percurso abrindo o debate sobre a pesquisa em educação explorando Ulisses e o mito do esclarecimento, de Adorno e Horkheimer (1985), para dizer que este era o contexto da crise: "Em seu interior podemos pensar a pesquisa, de modo geral, e a pesquisa em educação, de modo particular" (MORAES, 2000, p. 7).

\section{Problemas de pesquisa em Educação}

Alguns textos da autora centralizaram de forma crescente a relação entre o campo educacional, a pesquisa e a produção de conhecimento. "Recuo da teoria: dilemas em pesquisa em educação" (MORAES, 2001a), "Recuo da teoria" (2003c) e "Indagaçóes sobre o conhecimento no campo da educação” (MORAES, 2007) são expressão dessa abordagem. Outras reflexóes se seguiram, ampliando suas ideias em relação ao conhecimento e à educação: "Os 'pós-ismos' e outras querelas ideológicas" (MOARES, 1996), "A ética pragmática do Neoconservadorismo: Richard Rorty" (MORAES, 1997), "Ceticismo epistemológico, ironia complacente: até onde vai o neopragmatismo rortyano" (MORAES, 2001b) "Filosofia terapêutica, educação de resultados e o ethos neodarwinista dos dias atuais" (MORAES, 2002a), "O renovado conservadorismo da agenda pós-moderna" (MORAES, 2004).

Este conjunto de reflexões repercutiu também em pesquisas sobre a formação docente: "Educação light, que palpite infeliz. Indagações sobre as propostas do MEC para a formação de professores" (MORAES; TORRIGLIA, 2000), Politica educacional (MORAES; EVANGELISTA, SHIROMA, 2004), "Sentido do ser docente e da construção de seu conhecimento" (MORAES; TORRIGLIA, 2003) "Proposiçôes sobre produção de conhecimento e políticas de formação docente" (MORAES, 2003b), "Incertezas nas práticas de formação e no conhecimento docente" (MORAES, 2004a), Iluminismo às avessas (2003a), entre outros.

Como vemos, o caminho percorrido pela autora teve vários desdobramentos. Podemos afirmar que seus escritos, sempre em interlocução com a filosofia e as ciências sociais, foram frutos de estudos e debates, de participação em grupos, de aulas, e se materializaram com o intuito 
de desvendar a problemática do conhecimento no campo educacional. Destacamos, ademais, que Moraes articulou suas convicçóes teóricas com diversas participaçóes e intervençóes, a exemplo da assunção ao cargo de coordenadora do Programa de Pós-Graduação em Educação da UFSC, de membro da Capes e do CNPq, como palestrante e professora.

No afâ de compreender a problemática educacional tal como discutida pela autora, relacionamos algumas ideias, esclarecendo, contudo, que esta relação não corresponde necessariamente ao movimento dos trabalhos de Moraes, posto que não tem uma linearidade hierárquica ou exata na produção. Notam-se, em seus textos, constantes idas e voltas às perguntas postas pela atualidade, às demandas da conjuntura e à busca de respostas, indicando os fenômenos e procurando sua gênese, seus desdobramentos e as tendências vigentes.

No texto "Recuo da teoria" - e no contexto dos desestabilizadores efeitos da reestruturação socioeconômica em escala planetária - Moraes (2003c, p. 152) explicava que

Se o mundo virou pelo avesso, a educaçáo deve acompanhá-lo na reviravolta. Caem em desuso a escola tradicional, a educação formal, as antigas referências educacionais. O discurso é claro: é preciso, agora, elaborar uma nova pedagogia, um projeto educativo de outra natureza e assegurar o desenvolvimento de competências, valor agregado a um processo que, todavia, não é o mesmo para todos.

Acrescentava que, para algumas pessoas, se exigem níveis crescentemente altos de aprendizagem assentados sobre um domínio teórico-metodológico que a experiência empírica, por si só, é incapaz de garantir. Para a maioria, porém, bastam as competências no sentido genérico que o termo adquiriu nos últimos tempos, as quais permitem a sobrevivência nas franjas de um mercado de trabalho com exigências diferenciadas e níveis de exclusão jamais vistos na história, assinalando que, como se sabe, o "[...] capitalismo tornou-se um espetáculo global para a minoria” (GRUPO KRISIS, 2000).

Criticava fortemente a ideia de uma educação salvacionista reduzida à aprendizagem da “[...] manipulação de 'pacotes' prontos de conhecimento, de acordo com os indicadores de desempenho e aceitação no mercado e a 
posição que nele ocupamos" (MORAES, 2003, p. 153). Desse modo, não é casual que apontasse, seguidamente, o foco central de sua exposição: a discussão teórica gradativamente suprimida ou relegada a um segundo plano nas pesquisas educacionais. Este fato (ou esta constatação), segundo ela, acarretaria implicaçóes que poderiam repercutir, em curto e médio prazos, na própria produção de conhecimento na área. Articulando este assunto com a celebração do "fim da teoria", ela se perguntava: o que estaria direcionando o movimento que marginaliza os debates teóricos no campo educacional? Sem evitar nem negar as múltiplas possibilidades de resposta, indicava pistas, tendências que seriam aprofundadas nos seguintes trabalhos. Os elementos principais dessas pistas foram trabalhados por Moraes, evidenciando-se primeiramente as causa mais aparentes e, depois, buscando-se sua gênese. Como causa mais imediata, indicava a efetivação das políticas educacionais em níveis nacional e internacional que incentivam uma prática desprovida de reflexão, que parece responder bem às atuais demandas econômicas, além de se mostrar pragmaticamente mais eficaz. A partir dessa preocupação, a autora indica que, no Brasil,

[...] a definição de políticas nacionais que comprometem dramaticamente as condiçóes efetivas do ensino e da pesquisa na produção acadêmica notadamente as postas em prática na década de 1990 - instauram um clima propício à desagregação do ambiente acadêmico e, de acordo com o espírito da época, promovem o individualismo e descaracterizam as funçóes de docentes e pesquisadores. (MORAES, 2003, p. 155).

Com o intuito de ir além das causas mais visíveis, Moraes vai procurar na gênese da razão algumas respostas:

[...] as propostas que desqualificam a teoria têm origem na convicção da falência de uma determinada concepção de razão: a chamada razão moderna de corte iluminista, emblemática das culturas liberais do ocidente, produto de uma burguesia ainda em luta por sua definição e consolidação em face de seu "outro", feudal, 
aristocrático. A racionalidade iluminista abrangia e balizava um conjunto de princípios, idéias e práticas reguladoras que lhe permitia autorepresentar-se possuindo as condiçóes para estabelecer "a nítida demarcação entre racional e irracional, entre episteme e doxa, entre verdade e erro, entre ciência e não ciência”. (MORAES, 2003, p. 155).

Ademais, dessas demarcaçóes assinaladas, acreditava-se que esta racionalidade poderia assegurar as bases para a lei e a moralidade. Não é de surpreender, portanto, insistia a autora, "[...] que o desenvolvimento e o cultivo desta 'razão' tenha se tornado um objetivo educacional prioritário" (MORAES, 2003, p. 155).

Neste contexto de forte crítica a uma razão capaz de elaborar normas, construir sistemas de pensamento e de ação e da habilidade racional de planejar de forma duradoura a ordem social e política, a autora assinalou uma sanitarização da "racionalidade moderna e iluminista", que aparentemente não deixou espaço para propostas alternativas:

[...] vertendo-se fora não só as impurezas detectadas pela inspeçáo crítica, mas o próprio objeto da inspeção; não apenas os métodos empregados para validar o conhecimento sistemático e arrazoado, mas a verdade, o racional, a objetividade, enfim, a própria possibilidade de cognição do real. (MORAES; DUAYER, 1998, p. 68).

Esta armadilha trouxe, como diria Brecht (1977), "uma confusão organizada". Assim, e sem esgotar a complexidade do tema do conhecimento, temos uma forte crítica a um tipo de racionalidade, gerando-se, consequentemente, um recuo da teoria correspondente a esta época, cética e pragmática, em que se prioriza uma metafísica de perpétuos presentes, sendo este ceticismo não apenas epistemológico, mas ético e político.

Nessa direção, se perguntava: como definir padróes epistemológicos, educacionais, éticos ou políticos se não se dispóe mais da chancela da concepção moderna e iluminista de racionalidade? Como pensar a ética ou o conhecimento sem o suporte de uma subjetividade livre, racional, consciente 
e dotada de vontade e responsabilidade? Como e o que ensinar, se todas as interpretaçóes e perspectivas são igualmente válidas e sem referentes? Como e o que ensinar, se a mudança conceitual repousa na persuasão e não na razão; se conceitos científicos são apenas mais um entre os múltiplos jogos de linguagem?

Por essa via, a autora oferece-nos outro tema de suma importância para o campo educacional: o sutil exercício linguístico posto em prática em anos recentes, mostrando como termos e conceitos foram absorvidos pela pragmática retórica. Indica que uns foram "[...] naturalizados - o capitalismo, por exemplo -, alguns foram construídos, outros re-significados, modificados ou substituídos por termos mais convenientes”, e ainda,

O termo igualdade, entre outros tantos exemplos, cedeu lugar à eqüidade, o conceito de classe social foi substituído pelo de status socioeconômico, os de pobreza e riqueza pela peculiar denominação de "baixo" e "alto" ingressos sociais. (MORAES, 2003, p. 158).

Esta ressignificação, que obviamente vai além da linguística por sua repercussão na prática social, procura - em seus mais espúrios trâmites de harmonia social - gerar consenso. Por um lado, lança mão da repetição do mesmo e, por outro, da banalização de problemas dados como antigos ou "fora de época". Por isso, a compreensão do campo das políticas educacionais e da conjuntura atual lhe permitiu dizer que "O processo reformista se fez legitimar pela arquitetura de um forte clima de consenso na sociedade" e que o complemento necessário ao consenso foi a pragmática construção de um novo vocabulário,

[...] suporte à criação de novos desenhos conceituais que realizou a ressignificação de conceitos, categorias e termos, de modo a torná-los condizentes com os emergentes paradigmas que referenciaram as reformas almejadas para a educação brasileira e latinoamericana. Conceitos como competência, destreza, consenso, sociedade civil, democracia, cidadania, tolerância, edificação, professor, solidariedade, racionalidade, verdade, conhecimento, entre outros, foram sorvidos pela retórica em vigor, adquirindo 
sentido e significados adequados aos novos tempos. (MORAES; DA SILVA; HILLESHEIN; GRANADO, 2003, p. 3).

Esta adesão pragmática na educação, acompanhada por uma avalanche de conceitos transmutados em metáforas sem compromisso com o conhecimento objetivo e crítico da realidade social capitalista, foi amplamente discutida por Moraes nos estudos realizados sobre o neopragmatismo de Richard Rorty. Sem pretender esgotar a importância do pensador e sua obra sobre as questóes da filosofia, história, política, democracia, entre outras, seu foco recaía sobre seus efeitos diretos, mas não perceptíveis, sobre o campo educacional.

No texto "O renovado conservadorismo da agenda pós-moderna" (MORAES, 2004) ${ }^{4}$, a autora, entrando no debate acerca da "eventual morte" do que se convencionou chamar de pós-moderno ou pós-modernismo, em torno da existência ou não de uma "agenda pós-moderna”, recuperará algumas reflexóes anteriores expressas nos textos "Os 'pós-ismos' e outras querelas ideológicas” (MORAES, DUAYER, 1996), no qual demarca o pós-moderno como uma agenda, "História, estórias: morte do real ou derrota do pensamento?” (MORAES, DUAYER, 1998), em que discutem as irresoluçóes epistemológicas presentes no vazio aberto pelo colapso do real proposto pelos pós-modernos, e "Ceticismo epistemológico, ironia complacente: até onde vai o neopragmatismo rortyano” (MORAES, 2001b), em que apresenta as críticas de Rorty à filosofia ocidental, suas concepçóes de conhecimento e de verdade, e seu consequente ceticismo epistemológico.

Nessa produção sobre o renovado conservadorismo da agenda pósmoderna (MORAES, 2004), ela coloca um chamativo subtítulo - "outra fronteira que se rompe: a entre conhecer e melhor usar as coisas" -, que parafraseia uma indicação de Rorty e insiste em que o autor, ao conclamar uma revisão da história, assinala algumas outras metas: “[...] a de livrar-se de vez da concepção kantiana de conhecimento; a de afastar a epistemologia e a metafísica como disciplinas possíveis; e; então, apresentar uma filosofia terapêutica e edificante em lugar de construtiva e sistemática" (MORAES, 2004, p. 346).

Nestas metas, para ela, e em termos rortyanos, "[...] não haveria atividade chamada 'conhecimento' que tenha natureza a descobrir" e seria 
“[...] o vocabulário da prática e não da teoria [...] o que pode revelar alguma coisa útil sobre a verdade" (MORAES, 2004, p. 346). Desse modo, e sempre na linha de pensamento do autor, "[...] há que romper a fronteira entre conhecer e usar as coisas, pois não se trata mais de obter um conhecimento objetivo da realidade, mas, somente, de indagar como utilizá-la melhor" (MORAES, 2004, p. 346). Nessa perspectiva, ficam comprometidas a verdade e a objetividade, ou seja, perde-se o sentido da discussão sobre o que seriam a interpretação e a apreensão corretas da realidade. Cabe destacar que, em nota de rodapé, Moraes faz uma analogia entre os princípios pedagógicos do "aprender a aprender" e o privilégio e a prioridade das chamadas e tão conhecidas competências na escola, frisando que qualquer semelhança não seria mera coincidência.

Juntamente com Duayer, a autora problematiza as premissas rortyanas e sua consequente negação da ciência e do conhecimento objetivo; de acordo com a proposta pragmática,

[...] não se trata de negar a existência da realidade, refuta, porém, a possibilidade mas, antes, de refutar a possibilidade de formular um teste independente - isto é, independente da linguagem, dos interesses humanos - capaz de medir o grau de acuidade da representação, vale dizer, de sua correspondência com uma realidade determinada anterior e independentemente do teste (MORAES; DUAYER, 1997, p. 121).

Desta forma, apesar de que se afirma a existência da realidade, esta postura torna impossível o acesso a ela. Assim, no contexto do movimento pragmático de substituição das "questôes teóricas" pelas "questôes práticas", as únicas restrições à pesquisa para Rorty estão "[...] no campo da conversação e não na natureza do objeto da mente e da linguagem" (MORAES, 2004, p. 348).

Não em vão, Moraes estava inquieta com o avanço do ceticismo epistemológico, ceticismo que, para ela, transcende ou não se restringe simplesmente "a controvérsias sobre o conhecimento e os critérios de validação". Ao contrário, é uma “[...] discussão ideológica de largo espectro na qual se concentram e se enfrentam vários protagonistas em presença na cena intelectual contemporânea, inclusive o neopragmatismo rortyano e sua proposição de verdade como consenso" (MORAES, 2004, p. 349). 
Nesse processo, desvenda ou insiste em não cair na falácia proposta pela agenda pós-moderna: metafísica ou relativismo; metanarrativa ou histórias fragmentárias; universalidade ou segmento; teoria totalitária ou nenhuma teoria; verdade como adequação ou verdade como consenso; neopragmatismo ou nenhum pensamento (MORAES, 1996, 2003).

Para superar esta armadilha posta de aparentes dicotomias, tornou-se necessário para Moraes aprofundar autores como Marx, Lukács, Baskhar, entre outros, para fundamentar a complexidade do mundo e a possibilidade de conhecer o mundo objetivo, já que, “[...] para além da objetividade neopragmática definida no consenso, para além de 'ser causado', para além da metáfora da amplitude", há as relações

[...] tensas e complexas do que alguns de nós denominamos de ontologia, a efetividade complexa do ser social, o real na essencialidade de relações concretas que instituem e constituem relaçóes econômicas, políticas e culturais no processo contraditório que é produto do agir humano. Por isso a complexidade do ser social é inteligível, por isso mesmo é efetividade real aberta ao conhecimento, à correta compreensão e à intervenção. (MORAES, 2003, p. 194).

$\mathrm{Na}$ mesma linha de pensamento, cabe destacar o texto de Moraes e Müller (2003) "História e experiência; contribuiçōes de E. P. Thompson à pesquisa em educação", no qual os autores desenvolvem algumas ideias que permitem superar outra dicotomia: a opção entre as metanarrativas suprahistóricas e as narrativas fragmentadas. Nesse artigo, os autores assinalam a importância de mostrar que as proposiçóes thompsonianas "[...] podem inspirar a reflexão filosófica acerca da pesquisa em educação e dos problemas educacionais do mundo contemporâneo" (MORAES; MÜLLER, 2003, p. 4). Assim, o complexo educativo - complexo estruturado da totalidade social - é em sua essência histórico, lembrando que só nesse âmbito os objetos de pesquisa em Educação (sem perder seu caráter específico) ganham inteligibilidade.

Segundo Moraes e Müller (2003), com Thompson o tema da experiência e da cultura é articulado constituindo "[...] um ponto de junção entre estrutura e processo, entre as determinaçóes objetivas do ser social 
e a possibilidade do agir e da intervenção humanos: ${ }^{5}$ neste sentido, são "conceitos de junção" (junction-concepts)". ${ }^{6}$ Nessa direção, para Thompson,

[...] a experiência, "sem bater na porta", constitui e nega, opóe e resiste, estabelece mediaçóes, é espaço de prática, intervenção, obstaculização, recusa, é processo de formação de identidades de classe e, poderíamos acrescentar, de gênero, de geração, de etnias. Processos dialeticamente articulados que ela, a experiência, expressa de forma privilegiada (MORAES; MÜLLER, 2003, p. 341).

Para a autora, no campo educacional estava-se equacionando um conceito vulgar de experiência que estabelece sua equivalência à empiria. E esta "[...] construção empiricista da experiência induz ao relativismo e à passividade e à aceitação de todo o status quo" (MORAES; TORRIGLIA, 2000, p. 53).

Consideramos que essa linha de reflexão aponta para a necessidade de aprofundar mais o conceito de experiência, em especial na formação docente, como assim também a discussão do conceito de cultura e suas implicaçóes para o debate educacional contemporâneo, mas isso fugiria ao objetivo deste texto.

\section{Algumas consideraçóes finais: nem o real morreu nem o pensa- mento está derrotado}

As categorias centrais do pensamento de Moraes, que se desdobraram a partir de seu interesse pela produção do conhecimento e, portanto, da ciência, particularmente do papel da teoria, da experiência, da ressignificação do conceito de sociedade civil, da totalidade social, da linguagem, da representação, da verdade, permitiram sua articulação com o campo educacional. $\mathrm{O}$ mergulho nestas problemáticas estava em todas as atividades acadêmicas, desde as teses e dissertaçóes que orientava até sua atuação como intelectual em esferas de decisóes políticas educacionais. Moraes teve sempre clareza de que o lugar da Pós-Graduação em Educação era o lócus privilegiado da produção de conhecimento na área e para pensar sobre o próprio conhecimento da educação. ${ }^{7}$ 
Na interlocução com seu tempo, capturou os movimentos de transição e de mudança da esfera educacional, procurando captar a sutileza das mediaçóes entre as movimentaçóes socioeconômicas, as lutas políticas e os processos objetivos e subjetivos que acontecem nos mais diversos espaços educacionais, desde a Educação Infantil até a pós-graduação.

Afirmamos que o recuo da teoria, tantas vezes assinalado por Moraes, expressa o retrocesso de um tipo de teoria que não defende nem se preocupa com o conhecimento do mundo objetivo, e, portanto, não interessam as indagaçóes sobre a verdade e a capacidade cognoscente dos sujeitos. $\mathrm{O}$ clima de uma sociedade do conhecimento sem pretensóes reais de conhecer encaixa-se como uma luva no espírito pragmático dos novos tempos, dizia Maria Célia, sem se surpreender. Tal visão foi indicada no livro Iluminismo às avessas (2003), no qual está inscrita a reviravolta que sintetiza a ironia da "sociedade do conhecimento". Nas suas palavras:

No âmbito desta problemática pode-se ousar uma proposição, ainda inicial e que é o irônico mote do título do livro: ao propugnar a sociedade contemporânea como "do conhecimento" e afirmar o conhecimento como fundamento das formas de organização social e de produção em escala mundial, o padrão civilizatório contemporâneo parece ressuscitar os velhos tempos de glória iluminista. Trata-se, porém, de um iluminismo às avessas, invertido e estranhado de boa parte de seu sentido original. (MORAES, 2003, p. 17).

Tal iluminismo - às avessas - demonstra e explicita um “[...] conhecimento das virtudes 'intrinsecamente democráticas', sobretudo a de que é infinitamente ampliável. Tal característica, a de poder dilatar cada vez mais seu horizonte, faz do conhecimento um bem, um recurso e um serviço que não se desgasta e, portanto, concede-lhe lugar importante como aporte à produção" (MORAES, 2003, p. 18). Nesse contexto de extrema saturação de informaçóes, a autora mostra como esse iluminismo invertido “[...] fez perder no caminho o componente teórico-crítico essencial, a racionalidade capaz de reflexionar sobre si mesma e sobre a natureza de seu objeto, privando-se, assim, do 'incondicional impulso emancipatório que está na raiz da vocação filosófica” (MORAES, 2003, p. 18). 
Esta situação, que preparou e atendeu o espírito pragmático denunciado por Moraes e outros pesquisadores na área educacional -, introduz, por um lado, "[...] o conhecimento instrumental ou técnicooperatório; e, por outro, a associação vulgar das empirias, um 'saber-fazer' conformado na aceitação do status quo". Este conhecimento instrumental e empobrecido bastaria para compreender um mundo altamente complexo.

Algumas teorias educacionais defendem que

[...] procedimentos e instrumentos de ensino operem praticamente no contexto interior à escola e possibilitem "a compreensão, de um lado, da importância da improvisação na prática pedagógica e, de outro, de um tipo de pesquisa vista como resposta imediata e não mediada pela reflexão". (EVANGELISTA, 2001, p. 9).

É importante afirmar também que o recuo da teoria não é independente dos sujeitos. Em outras palavras, o lugar do conhecimento não pode ser pensado sem os sujeitos que o produzem, os intelectuais. Nessa perspectiva, talvez não seja ousado pensar que assistimos um "recuo dos intelectuais", porque a teoria é a expressão da tarefa contínua da produção e da apropriação de alguma coisa por sujeitos. Moraes se recusou a acreditar no anunciado distanciamento da teoria e na substituição das "questões teóricas" pelas "questôes práticas". Esta batalha não foi fácil e foi motivo de embates, vividos muitas vezes pela autora em diversos meios e âmbitos acadêmicos.

Em seu último texto, "Indagaçóes sobre o conhecimento no campo da educação" (MORAES, 2007), assinalou que, nas pesquisas da área da Educação, permanecem os preceitos da agenda pós-moderna, sob múltiplas roupagens. Concorda com Medeiros (2004, p. 31) quando enuncia os três princípios básicos desta agenda:

- o princípio da naturalização do capital, que significa o entendimento de que as estruturas sociais existentes são efetivamente imutáveis;

- o princípio do atomismo social, que caracteriza a sociedade como um objeto constituído por uma simples agregação de indivíduos, e

- o princípio da afirmação abstrata de valores emancipatórios, que se refere à descrição dos valores como entidades absolutamente subjetivas, descoladas da práxis social. 
Para Moraes, tais princípios estão na base da desintegração do espaço público, do fetichismo da diversidade, da compreensão de que o poder e a opressão estão pulverizados em todo e qualquer lugar. Daí resulta a impossibilidade de se estabelecer uma base de resistência que possibilite o enfrentamento da realidade objetiva.

Moraes nos deixa um legado e muitos desafios.

O legado é o alerta quanto à necessidade de estarmos conscientes de que, na perspectiva cética e relativista,

[...] o mundo social é esvaziado de qualquer dimensão estrutural duradoura que apenas o esforço teórico pode alcançar. Por conseguinte, a teoria que se constrói, nivelada em seu conjunto por indiferenciado relativismo, restringe-se a descrever e, quando muito, a nomear as formas fenomênicas do cotidiano. (MORAES, 2007, p. 2).

Esta denúncia lhe permitiu abraçar firmemente a causa da transformação radical da realidade social, tendo em vista a superação da sociedade comandada pela lógica do capital, que requer uma correta compreensão das estruturas e da dinâmica do mundo. Assim, não claudicou na crítica ao que estava dado e estabelecido, como Brecht diria e Moraes concordaria:

Desconfiai do mais trivial, na aparência singelo. E examinai, sobretudo o que parece habitual. Suplicamos expressamente: não aceiteis o que é de hábito como coisa natural, pois em tempos de desordem sangrenta, de confusão organizada, de arbitrariedade consciente, de humanidade desumanizada, nada deve parecer natural, nada deve parecer impossível de mudar. (BRECHT, 1977, p. 45)

Em sua última intervenção pública, pronunciou sua frase favorita: a teoria tem consequências! Este é o desafio que nos deixou, nada mais e nada menos que a decisão de escolher, dizendo:

A opção está posta, escolhermos uma teoria que 
contribua para perenizar o presente e administrar o existente, como as várias versôes da epistemologia da prática, particularmente na educação ou uma teoria que proceda à análise crítica do existente, que informe a prática científica consciente de si mesma, pois é o processo histórico-crítico do conhecimento científico que nos ensina (como seres sociais) a capacidade emancipatória, que nos torna conscientes de nosso papel de educadores que não ignoram que a transmissão do conhecimento e da verdade dos acontecimentos são instrumentos de luta e têm a função de ser mediação na apreensão e generalização de conhecimentos sobre a realidade objetiva, sob a perspectiva de domínio sobre a realidade segundo as exigências humanas. (MORAES, 2007, p. 14).

Moraes deixou abertas muitas portas que se estendem aos intelectuais e pensadores que tiveram a possibilidade, por diferentes vias, de compartilhar com ela sua paixão pelo estudo e pela construção irredutível de uma vida plena de sentido, que isso implicava, entre outras coisas, um desenvolvimento pleno da personalidade humana.

\section{Notas}

1 Para conferir algumas de suas publicações, sugerimos: Moraes (1994, 1995, 1996, 1999a, 1999b, 2000, 2001a, 2001b, 2002a, 2002b, 2003a, 2003b, 2004a, 2004b, 2004c, 2006a, 2006b, 2007), Moraes e Torriglia (2000, 2003), Moraes e Duayer (1997, 1998), Moraes e Küenzer (2005), Moraes e Horta (2005), Moraes, Evangelista e Shiroma (2003, 2004), Moraes, Pacheco e Evangelista (2001, 2003), Moraes e Frota (2001) e Moraes e Müller (2003).

2 Indagaçóes sobre o conhecimento no campo da educação... (2007).

3 Ao abrir debates sobre a conjuntura/estrutura e base/superestrutura, assinalava que, muitas vezes, eram confundidas. Para explicar este equívoco, Moraes, auxiliando-se de texto de Italo Calvino Palomar (1983) destacava a analogia entre conjuntura/estrutura com as ondas e o mar: o oceano representaria a estrutura, ao passo que as ondas representariam a 
conjuntura: há um mar em movimento, e esse movimento faz com que ondas apareçam na superfície. Essas ondas obviamente são impulsionadas nesse processo profundo do oceano. Compreender a conjuntura significa compreender o processo como um todo, movimento dinâmico, processual. Se há o congelamento de um determinado momento, há o congelamento da conjuntura e, obviamente, das categorias. Voltando à analogia do mar e das ondas, pode-se dizer que é impossível congelar uma onda. Da mesma forma, é difícil congelar uma determinada conjuntura.

4 Este texto é uma síntese que permite compreender as influências teóricas presentes na pesquisa educacional no Brasil. Nele a autora procura explicar alguns dos impactos derivados da crítica a um tipo de razão, a iluminista, colocando nesse movimento a ampla agenda pós-moderna, com uma pluralidade de propostas e interpretaçóes gerando complexos e contraditórios desdobramentos: o que se chamou de "virada linguística" e uma renovaçáo do neopragmatismo assentadas nas proposiçóes de Richard Rorty, que denominou de "virada pragmática" (MORAES, 2004).

5 Como indica Müller (2002), a noção de junction concepts é resultado de um conjunto de discussóes entre Thompson e Raymond Williams, como também o conceito de determinação e o de "estruturas de sentimento", desenvolvido por Williams e incorporado por Thompson. Cf. Williams (1979, p. 89 e 134-135).

6 Moraes e Müller, (2003, p. 340) explicam que “[...] Thompson (1978, p. 363) afirma que na cultura os sujeitos lidam com o sentimento como normas, obrigaçóes familiares e de parentesco e reciprocidades, como valores, ou mediante formas mais elaboradas na arte ou nas convicçóes religiosas" e que “[...] Os valores não são apenas 'pensados', nem 'chamados'; são vividos e emergem no interior do mesmo vínculo com a vida material e as relaçóes materiais em que surgem nossas idéias. São as normas, regras, expectativas etc., necessárias e aprendidas (e 'aprendidas' no sentimento), no habitus de viver; e aprendidas, em primeiro lugar, na família, no trabalho e na comunidade imediata. Sem esse aprendizado a vida social não poderia ser mantida e cessaria toda produção" (THOMPSON, 1978, p. 367 apud MORAES; MÜLLER, 2003, p. 340).

7 Moraes publicou vários textos sobre a Pós-Graduação, cujas indicações encontram-se nas referências. 


\section{Referências}

ADORNO, T. W.; HORKHEIMER, M. Dialética do esclarecimento. Rio de Janeiro: Jorge Zahar, 1985.

AHMAD, A. Culture, nationalism, and the role of intellectuals. Monthly Review, New York, v. 47, n. 3, p. 41-58, jul./aug. 1995.

ANDERSON, P. A civilização e suas interpretaçóes. Praga, São Paulo, n. 2, jun.1997.

BHASKAR, R. Societies. In: The possibility of naturalism.

Brighton: The Harvester Press, 1979.

. Scientific realism and human emancipation. London: Verso, 1986.

Plato, etc.: the problems of philosophy and their resolution. London: Verso, 1994.

. Reclaiming reality: a critical introduction to contemporary philosophy. London: Verso, 1993.

. A realist theory of science. London: Verso, 1997.

BRECHT, Bertolt. Nada é impossível de mudar. In: Antologia poética. Belo Horizonte: Leitura, 1977.

CALVINO, I. Palomar. Torino: Giulio Einaudi, 1983.

GRUPO KRISIS. Manifesto contra o trabalho. Cadernos do Labur, São Paulo, n. 2, 2000.

JAMESON, F. The ideologies of theory: essays, 1971-1986. London:

Routledge, 1988. v. II.

JORNADA DE INVESTIGACIÓN EN EDUCACIÓN:

EDUCACIÓN Y PERSPECTIVAS: CONTRIBUCIONES TEÓRICAS Y METODOLÓGICAS EN DEBATE, 5., 2007, Córdoba, Argentina. Anais... Córdoba, Argentina: Universidad Nacional de Córdoba, 2007. Conferencia principal.

LUKÁCS, Georg. A reprodução. In: ___ Para uma ontologia do ser social. Roma: Riunit, 1990. cap. 2. Mimeografado. 
LUKÁCS, G. O trabalho. Alagoas: UFA, 1984.

. As bases ontológicas do pensamento e da atividade do homem. Temas de Ciências Humanas, São Paulo, v. 4, p. 1-18, 1978.

. Ontologia do ser social: os princípios ontológicos fundamentais de Marx. São Paulo: LECH, 1979.

MARX, K. A questão judaica. Lisboa: Edições 70, 1964.

. O capital: livro 1. Rio de Janeiro: Civilização Brasileira, 1974. v. 1.

. O capital: livro 1. São Paulo: Abril Cultural, 1983. v. 1.

. O capital: livro 3. Rio de Janeiro: Civilização Brasileira, 1974 a.

v. 6 .

MEDEIROS, J. L. Sete teses sobre o mundo social (e sobre o conhecimento deste mundo). Rio de Janeiro: UFRJ, 2004. Texto não publicado, mimeografado.

MORAES, M. C. M. Anotações para a aula: algumas questôes sobre a "Razão ocidental". Florianópolis: PPGE/UFSC,1998. (Curso de doutorado, disciplina Teoria e educação, 1998/2).

Anotaçôes para a aula: algumas questôes sobre a "Razão ocidental”. Florianópolis: PPGE/UFSC, 2000. (Curso de doutorado, disciplina Questóes epistemológicas na Pesquisa em Educação, 2000/1).

- Avaliação na Pós-Graduação brasileira: novos paradigmas antigas controvérsias. In: BIANCHETTI, Lucídio; MACHADO, Ana Maria Netto (Org.). A buissola do escrever: desafios e estratégias na orientação de teses e dissertaçóes. São Paulo: Cortez, 2002b. v. 1, p. 187-214.

. Ceticismo epistemológico, ironia complacente: até onde vai o neopragmatismo rortyano? Educação nas Ciências, Ijuí, ano 1, n. 1, p. 157-189, jan./jun. 2001 b.

. Comte e o positivismo: profetas da modernidade. Revista de Filosofia SEAF, Rio de Janeiro, p.109-147, 1995.

- Desrazão no discurso da história: razōes. Revista de Filosofia SEAF, Rio de Janeiro, p. 177-204, 1994 a. 
MORAES, M. C. M. Entrevista Maria Célia Marcondes de Moraes. Entrevistadores: Ana Maria Machado e Lucídio Biancheti. Revista Brasileira de Educação, v.13 n. 38, p. 369-386, maio/ago. 2008.

. Epistemological scepticism, complacent irony: investigations concerning the neo-pragmatism of richard rorty. In: SAWCHUK, P. H.; DUARTE, N.; Elhammoumi, M. (Org.). Critical perspectives on activity, explorations across education, work, and everyday life. Cambridge: Cambridge University Press, 2006b. v. 1, p. 52-73.

Filosofia terapêutica, educação de resultados e o ethos neodarwinista dos dias atuais. Revista de Filosofia SEAF, Rio de Janeiro, v. 2, n. 2, p. 19-43, 2002a.

- Iluminismo às avessas como contexto da pós-graduação no Brasil. Educação Unisinos, São Leopoldo, RS, v. 8, n. 15, p. 79-101, 2004c.

(Org.). Iluminismo às avessas: produção de conhecimento e políticas de formação docente. Rio de Janeiro: DP\&A. 2003a.

Incertezas nas práticas de formação e no conhecimento docente. In: MOREIRA, A. F. et al. (Org.). Currículo: pensar, sentir e diferir. Rio de Janeiro: DP\&A, 2004a.

Indagaçóes sobre o conhecimento no campo da educação. In: REUNIÃO ANUAL DA ANPED, 30., 2007, Caxambu. Anais... Caxambu, 2007. GT 17.

. O nascimento da ciência moderna. In: HÜHNE, Leda Miranda (Org.). Fazer filosofia. Rio de Janeiro: UAPÊ, 1994b. p. 76-121.

Paradigmas e adesóes: temas para pensar a teoria e a prática em educação. Perspectiva, Florianópolis, v.17, n. 32, p.51-68, jul./dez. 1999.

. Os "pós-ismos" e outras querelas ideológicas. Perspectiva, Florianópolis, v. 14, n. 25, p. 45-60, jan./jun. 1996.

O processo de Bolonha vis a vis a globalização de um modelo de ensino superior. Perspectiva, Florianópolis, v. 24, p. 187-204, 2006a.

. Proposiçôes sobre produção de conhecimento e políticas de formação docente. In: MORAES, Maria Célia M. de et al. Iluminismo às 
avessas: produção de conhecimento e políticas de formação docente. Rio de Janeiro: DP\&A, 2003b.

MORAES, M. C. M. Recuo da teoria. In: MORAES, Maria Célia M. de et al. Iluminismo às avessas: produção de conhecimento e políticas de formação docente. Rio de Janeiro: DP\&A, 2003c.

. Recuo da teoria: dilemas da pesquisa em educação. Revista Portuguesa de Educação, Minho, PO, v. 14, n. 1, p. 7-25, 2001 a.

. Reformas de ensino, modernização administrada: a experiência de Francisco Campos - anos vinte e trinta. Florianópolis: UFSC/ CED/ NUP, 2000. (Teses NUP; 5).

- O renovado conservadorismo da agenda pós-moderna. Cadernos de Pesquisa, São Paulo, v. 34, n. 122, p. 337-357, maio/ago. 2004.

. Repensando a crise: "morte" do real ou derrota do pensamento? Florianópolis: CNPq, 1999. Relatório de pesquisa. Mimeografado.

; DA SILVA, Rute; HILLESHEIN, Valquíria; GRANADO, Maria Ligia. Sociedade do conhecimento: eficaz controle epistêmico do ato de conhecer. In: SEMINÁRIO INTERNACIONAL EDUCAÇÃO INTERCULTURAL, GÊNERO E MOVIMENTOS SOCIAIS: IDENTIDADE, DIFERENÇA E MEDIAÇÓES, 2., 2003, Florianópolis. Anais eletrônicos... Florianópolis: CNPq/FUNICITEQ/ UFSC, 2003. v. 1. p. 1-15. Disponível em: <http://www.rizoma.ufsc.br/ pdfs/51-of7b-st4.pdf >. Acesso em: 4 mar. 2010.

; DUAYER, Mario. Ética pragmática do neoconservadorismo: Richard Rorty. In: GERD, Bornheim et al. (Org.). Ética. Rio de Janeiro: UAPE: SEAF, 1997. p. 99-140.

; __ . História, estórias: morte do real ou derrota do pensamento? Perspectiva, Florianópolis: CED/UFSC, ano 16, n. 29, p. 63-74, jan./jun. 1998.

; EVANGELISTA, Olinda; PACHECO, J. A. B. Políticas educacionais nos anos 90: a formação de professores no Brasil e em Portugal. Educar em Revista, Curitiba, PR, n. 1, p. 185-200, 2001. ; SHIROMA, Eneida Oto. Política educacional. 3. ed. Rio de Janeiro: DP\&A, 2004. v. 1. 
MORAES, M. C. M.; FROTA, P. R. Calculando com Galileu: os desafios da ciência nova. Linguagens Educação e Sociedade, Teresina, PI, v. 6, n. 6, p. 13-27, 2001.

; HORTA, J. S. B. O sistema Capes de avaliação da pósgraduação: da área de educação à grande área de humanas. Revista Brasileira de Educação, Rio de Janeiro, v. 30, n. 30, p. 95-116, 2005.

; KÜENZER, Acácia Z. Temas e tramas da pós-graduação em educação. Educação \& Sociedade, Campinas, v. 26, n. 93, p. 1341-1362, 2005.

; MÜLLER, Ricardo. História e experiência: contribuições de E. P. Thompson à pesquisa em educação. Perspectiva, Florianópolis, v. 21, n. 2, p. 329-350, jul./dez. 2003.

; PACHECO, José Augusto; EVANGELISTA, O. (Org.). Formação de professores, perspectivas educacionais e curriculares. Porto, Portugal: Porto Editora, 2003. v. 1.

; SHIROMA, Eneida Oto; EVANGELISTA, Olinda. Ensino superior em tempos de adesão pragmática. In: MORAES, M. C. M. de (Org.). Iluminismo às avessas: produção do conhecimento e políticas de formação docente. Rio de Janeiro: DP\&A, 2003, v. 1, p. 129-150.

; TORRIGLIA, Patricia Laura. Educação light, que palpite infeliz: indagaçóes sobre as propostas do MEC para a formação de professores. Teias, Rio de Janeiro, ano 1, n. 2, p. 51-59, 2000.

; TORRIGLIA, Patricia Laura. Sentido do ser docente e da construção de seu conhecimento. In: MORAES, Maria Célia M. de. (Org.) Iluminismo às avessas. Rio de Janeiro: DP\&A, 2003.

NANDA, Meera. Restaurando o real: repensando as teorias da ciência sócio-construtivistas. Tradução de Mario Duayer. Socialist Register, v. 33, p.303-352, 1997.

NORRIS, C. What's wrong with postmodernism: critical theory and the end of Philosophy. Hampstead: Harvester/Wheatsheaf, 1990.

NORRIS, C. Reclaiming truth: contribution to a critique of cultural relativism. Durham: Duke University Press, 1996. 
NORRIS, C. Against relativism. Oxford: Blackwell, 1997.

NORRIS, C. Treading water in Neurath's Ship, Quine, Davidson, Rorty. Principia ( Revista Internacional de Epistemologia). Florianópolis: NEL/ Editora da UFSC, v. 2, n. 2, dez. 1998.

THOMPSON, E. P. The poverty of theory and others essays. London: Merlin, 1978. - A miséria da teoria ou um planetário de erros. Rio de Janeiro: Zahar, 1981.

WILLIAMS, R. Marxismo e Literatura. Rio de Janeiro: Zahar, 1979. WOOD, E. Modernidade, pós-modernidade ou capitalismo? Tradução de Maria Célia Marcondes de Moraes e Patricia Torriglia. In:

Capitalism and the information age. New York: Monthly Review Press, 1998.

. FOSTER, J. Em defesa da história: marxismo e pós-modernismo. Rio de Janeiro: Jorge Zahar,1999. 
Science and the production of knowledge in educational research: contributions of Maria Célia Marcondes de Moraes

\section{Abstract}

This article presents important issues related to the problem of science and production of knowledge in education raised in different works written by Maria Célia Marcondes de Moraes. Various theoretical problems concern the author, in particular the current skepticism and the profound contradictions in which meanings and concepts that signify theoretical practical movements present themselves with subtle and marked inversions and the impacts of this skepticism on the field and in educational research. Based on a materialist and critical ontological perspective, Moraes questions, discusses and delves into issues concerning the social being in its maximum expression.

Key words: Science. Production of Knowledge. Moraes, Maria Célia Marcondes de.

\section{La ciencia y la producción de conocimiento en la investigación educacional: contribuciones de Maria Célia Marcondes de Moraes}

\section{Resumen}

El presente artículo presenta algunos puntos relevantes explicitados en diferentes obras escritas por la Dra. Maria Célia Marcondes de Moraes en relación a los problemas de la ciencia y de la producción del conocimiento en la Educación. Diversos problemas teóricos preocupaban a la autora, en especial, el escepticismo vigente y las profundas contradicciones en las cuales sentidos y conceptos - que significan movimientos teórico-prácticos da realidad - se presentan con sutiles y marcadas inversiones impactando el campo y la investigación educacional. Con base en una perspectiva ontológica materialista y crítica Moraes indagó y profundizó estas cuestiones, y en especial, discutió el papel del ser educación en su máxima expresión.

Palabras clave: Ciencia. Producción de Conocimiento. Moraes, Maria Célia Marcondes de. 


\section{Patricia Laura Torriglia}

Rua Rita Lourenço da Silveira, 391, apto. 203

Lagoa da Conceição

Florianópolis - SC

CEP: 88062-060

E-mail:patrilaura@terra.com.br

\section{Newton Duarte}

Universidade Estadual Paulista Júlio de Mesquita Filho Faculdade de Ciências e Letras de Araraquara

Departamento de Psicologia da Educação

Rodovia Araraquar - Jaú km 1 - Bairro dos Machados

CEP: 14800-901 - Araraquara, SP

Caixa-Postal: 17 - Telefone: (16) 3301-6210

URL da Homepage: www.fclar.unesp.br

E-mail: newton.duarte@uol.com.br 